\title{
Advances in the Signaling Pathways Downstream of Glial-Scar Axon Growth Inhibitors
}

\author{
Armin Sami ${ }^{1,2}$, Michael E. Selzer ${ }^{1,3}$ and Shuxin $L i^{1,2 *}$ \\ ${ }^{1}$ Shriners Hospitals Pediatric Research Center, Lewis Katz School of Medicine at Temple University, Philadelphia, PA, \\ United States, ${ }^{2}$ Department of Anatomy and Cell Biology, Lewis Katz School of Medicine at Temple University, Philadelphia, \\ PA, United States, ${ }^{3}$ Department of Neurology, Lewis Katz School of Medicine at Temple University, Philadelphia, PA, \\ United States
}

Axon growth inhibitors generated by reactive glial scars play an important role in failure of axon regeneration after CNS injury in mature mammals. Among the inhibitory factors, chondroitin sulfate proteoglycans (CSPGs) are potent suppressors of axon regeneration and are important molecular targets for designing effective therapies for traumatic brain injury or spinal cord injury (SCI). CSPGs bind with high affinity to several transmembrane receptors, including two members of the leukocyte common antigen related (LAR) subfamily of receptor protein tyrosine phosphatases (RPTPs). Recent

OPEN ACCESS

Edited by:

Tommaso Pizzorusso,

University of Florence, Italy

Reviewed by:

Jerry Silver,

Case Western Reserve University, United States

Melissa R. Andrews,

University of Southampton,

United Kingdom

*Correspondence:

Shuxin Li

shuxin.li@temple.edu

Specialty section:

This article was submitted to Cellular Neuropathology, a section of the journal Frontiers in Cellular

Neuroscience

Received: 28 March 2020 Accepted: 22 May 2020 Published: 02 July 2020

Citation:

Sami A, Selzer ME and Li S (2020) Advances in the Signaling Pathways Downstream of Glial-Scar Axon Growth Inhibitors. Front. Cell. Neurosci. 14:174. doi: 10.3389/fncel.2020.00174 studies demonstrate that multiple intracellular signaling pathways downstream of these two RPTPs mediate the growth-inhibitory actions of CSPGs. A better understanding of these signaling pathways may facilitate development of new and effective therapies for CNS disorders characterized by axonal disconnections. This review will focus on recent advances in the downstream signaling pathways of scar-mediated inhibition and their potential as the molecular targets for CNS repair.

Keywords: scar inhibition, CSPG receptor, LAR, PTP $\sigma$, axon regeneration, intracellular signaling, RhoA, therapeutic target

\section{INTRODUCTION}

Axonal disconnections in the CNS usually result in permeant dysfunction. Although glial scars play supportive role in tissue repair (Anderson et al., 2016), eventually they create an inhibitory environment for axon regeneration and contribute to functional loss after CNS injuries (Bradbury et al., 2002; Jones et al., 2003; Busch and Silver, 2007). Glial scars not only form a physical barrier but also upregulate chondroitin sulfate proteoglycans (CSPGs) and other extracellular matrix (ECM) molecules, which potently inhibit regrowth of injured axons into and beyond the lesion (Bradbury et al., 2002; Jones et al., 2003; Busch and Silver, 2007). CSPGs are strongly expressed in the lesion penumbra, with even higher levels in the epicenter of the scar (Davies et al., 1997). CSPGs are mostly produced by reactive astrocytes and to a lesser extent by other cells, including oligodendrocytes and monocytes. CSPGs are also produced and secreted by neurons in the developmental and adult CNS (Galtrey and Fawcett, 2007; Dyck and Karimi-Abdolrezaee, 2015). The major CSPGs expressed in the CNS include lecticans (aggrecan, brevican, neurocan, and versican), phosphacan, and NG2 (Figure 1; Bandtlow and Zimmermann, 2000). Lecticans have similar N-terminal hyaluronanbinding domains and C-terminal globular domains with a unique lectin domain. Lectican core proteins (size: 97-262 kD) are connected by a dominant chondroitin sulfate glycosaminoglycan 


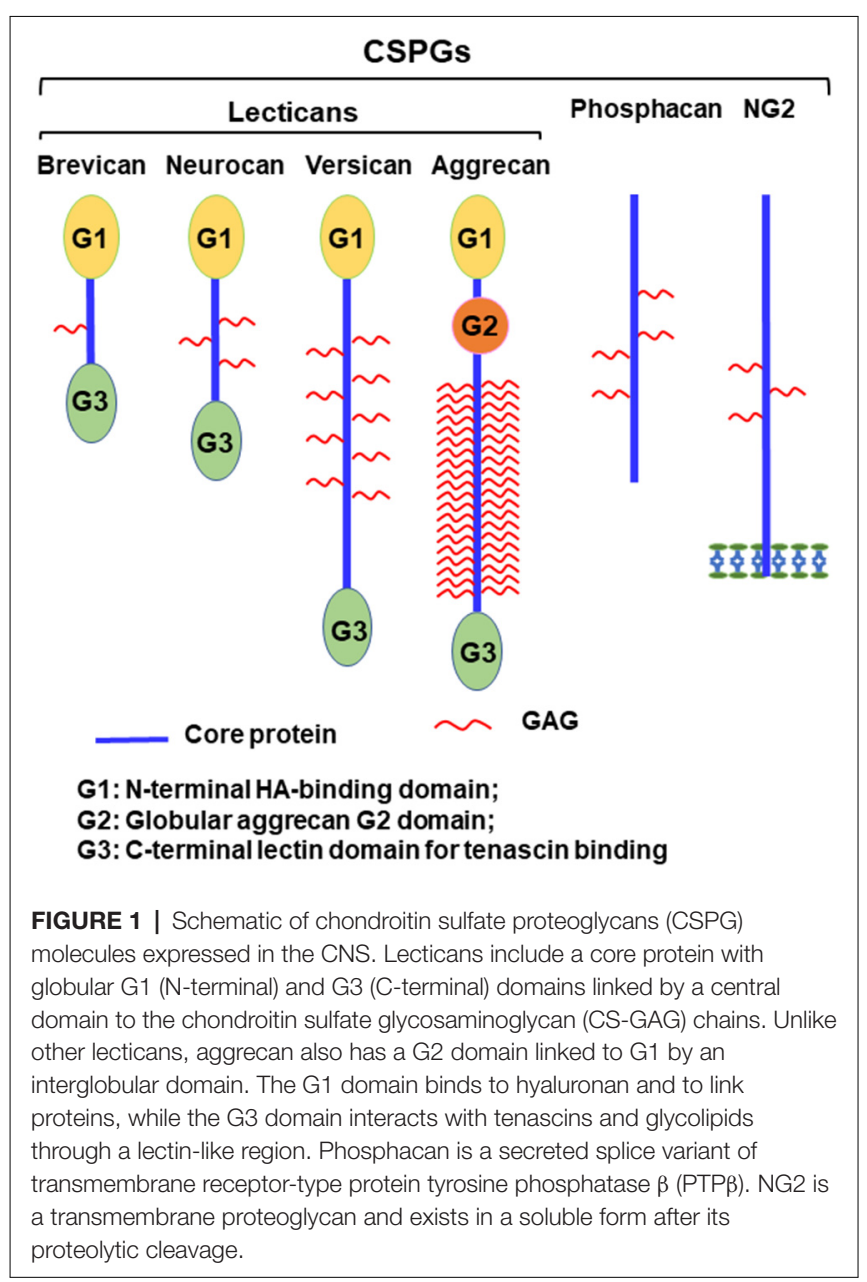

(CS-GAG) anchoring backbone, bound to one or more long-chain CS-GAG polysaccharides (Yu et al., 2017). Lecticans interact with carbohydrate and protein ligands in the ECM to form the perineuronal nets (PNNs; Yamaguchi, 2000), which are primarily composed of hyaluronan, CSPGs, tenascin R, and link proteins. Interactions among these molecules form a stable pericellular complex around synapses. PNNs are formed during late stages of CNS development and probably are essential for the reduction of plasticity seen in mature neurons (Kwok et al., 2011). Phosphacan is the extracellular domain of the transmembrane receptor-type protein tyrosine phosphatase $\beta$ (PTP $\beta)$. NG2 is a transmembrane CSPG that has no strong homologies to other proteins. CSPGs also are expressed in other systems and mediate proliferation, adhesion, migration, and growth of various cell types, such as neoplastic, immune ad cartilage cells.

CSPGs have been known to inhibit axonal growth for 30 years (Snow et al., 1990; McKeon et al., 1991), but the molecular mechanisms underlying their actions are not fully understood (Sharma et al., 2012; Ohtake and Li, 2015). All CSPGs have similar molecular structures, including GAG chains attached to the core proteins (Figure 1; Bandtlow and Zimmermann, 2000). Because digestion of GAGs by bacterial chondroitinase
$\mathrm{ABC}$ (ChABC), or prevention of GAG sulfation, largely reduces suppression of axon growth by CSPGs (Gilbert et al., 2005; Sherman and Back, 2008; Wang et al., 2008), sulfated GAG chains are particularly important for the inhibitory properties of CSPGs. Previously, CSPGs were shown to block growth by sterically hindering growth-promoting adhesion molecules (such as laminins/integrins) and/or facilitating suppression by repulsive molecules, such as Sema $3 \mathrm{a}$ and $5 \mathrm{a}$ (Condic et al., 1999; Kantor et al., 2004; Tan et al., 2011). During the past decade, several groups demonstrated the crucial roles of some transmembrane receptors in mediating CSPG inhibition. Two members of the LAR (leukocyte common antigen related) subfamily of receptor protein tyrosine phosphatases (RPTPs), PTP $\sigma$ and LAR, bind CSPGs with high affinity and mediate suppression of axon elongation by CSPGs (Figure 2; Shen et al., 2009; Fisher et al., 2011). Nogo receptor 1 (NgR1) and $\mathrm{NgR} 3$, two receptors for myelin associated inhibitors, also interact with CSPGs and may mediate some of their actions (Dickendesher et al., 2012).

The intracellular signals downstream of CSPGs are not completely known, but a number of signaling proteins at least in part mediate CSPG inhibition on neuronal growth, including Akt, glycogen synthase kinase $3 \beta$ (GSK-3 $\beta$ ), RhoA, and Erk (Powell et al., 2001; Monnier et al., 2003; Sivasankaran et al., 2004; Fu et al., 2007; Dill et al., 2008). Importantly, as the crucial functional receptors of CSPGs from the same LAR subfamily (Shen et al., 2009; Fisher et al., 2011), PTP $\sigma$ and LAR regulate neuronal functions by both convergent and divergent pathways (Ohtake et al., 2016). Several drugs that target the intracellular signals of CSPGs and other inhibitors have been moved to clinical trials for treating CNS axonal injuries (Kim et al., 2017; Wang et al., 2019). In this review, we focus on the progress that has been made recently in identifying CSPG signaling pathways and on their potential as the molecular targets for treating CNS injuries (Table 1), primarily in mammalian models. However, in mammals, it is difficult to do experiments with complete spinal cord transections and to distinguish regeneration of severed axons from collateral sprouting by spared fibers. Because these two processes may have different mechanisms (Jin et al., 2009), cautious investigators often refer to "axon growth" or "plasticity" rather than "regeneration" (Blesch and Tuszynski, 2009). Therefore, in some cases, we cite relevant work in non-mammalian species, particularly lampreys, which show robust but only partial axon regeneration after complete spinal cord transection, upregulate CSPGs at the injury site, and express homologs of the most molecules referred to in this review.

\section{SEVERAL TRANSMEMBRANE RECEPTORS MEDIATE GROWTH SUPPRESSION OF CSPG INHIBITORS}

The unique structures of CSPGs are essential for their function because digesting their GAG chains with enzymes, or preventing sulfation of GAG chains, greatly reduces their inhibition of axon growth (Gilbert et al., 2005; Sherman and Back, 2008; Wang et al., 2008; Brown et al., 2012). CSPGs are characterized 


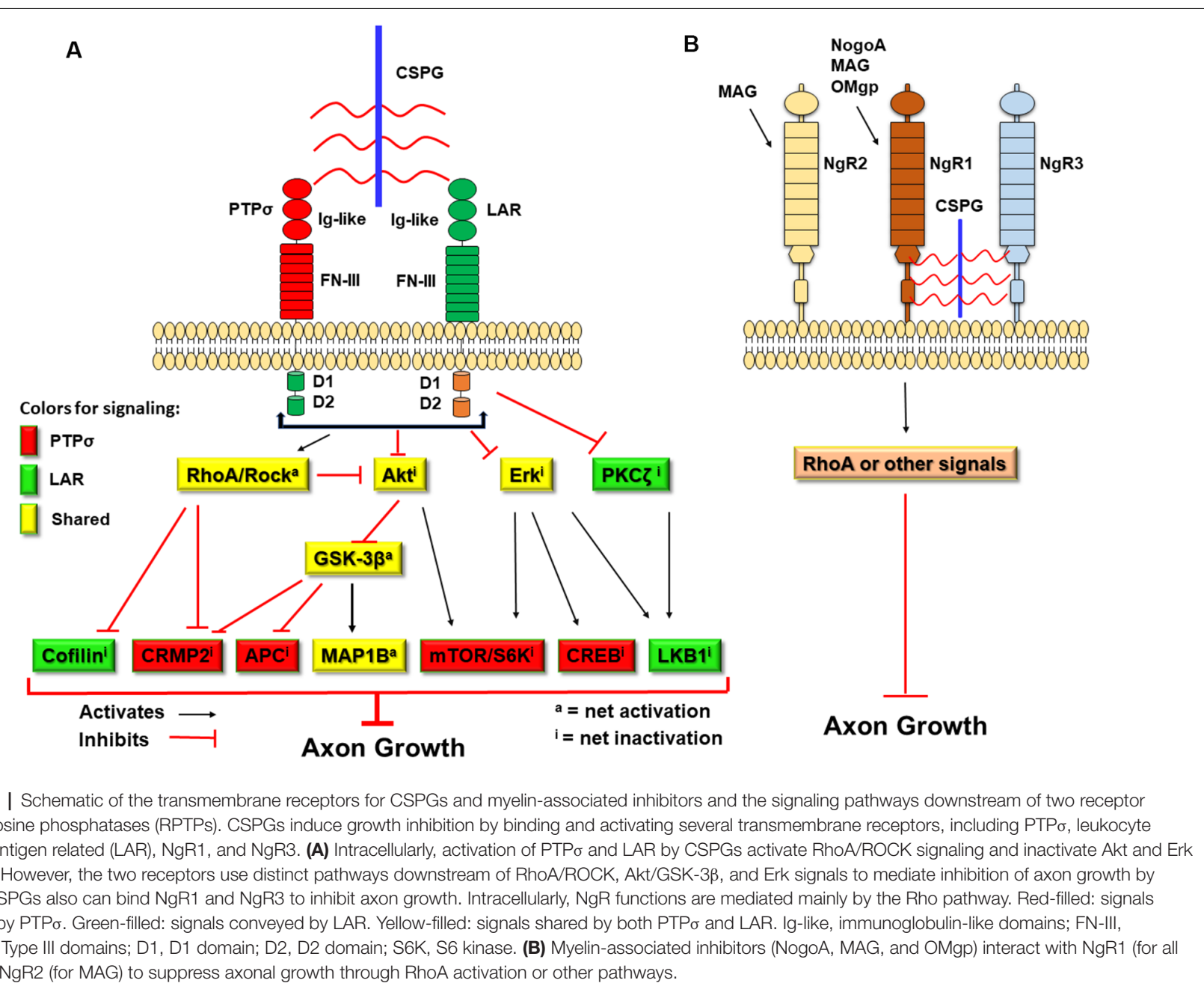

TABLE 1 | Summary of the major topics reviewed in this article.

\begin{tabular}{|c|c|}
\hline Major topics reviewed & Critical information on the topic \\
\hline Neuronal receptors for CSPGs & - PTP $\sigma$, LAR, NgR1, and NgR3 \\
\hline Potential intracellular signals to convey CSPG inhibition & - RhoA/ROCK, Akt/ GSK-3 $\beta$, PKC, and MARK \\
\hline Comparisons of the signals downstream of PTP $\sigma$ and LAR & $\begin{array}{l}\text { - Shared signals by both receptors: RhoA, Akt/GSK-3B, Erk, and MAP1B } \\
\text { - Major signals downstream of PTPr: CRMP2, APC, mTOR/S6 kinase, and CREB } \\
\text { - Major signals downstream of LAR: cofilin, PKC } \zeta \text { and LKB1 }\end{array}$ \\
\hline Clinical trial drugs to target CSPG downstream signals & $\begin{array}{l}\text { - RhoA inhibitors: cell-permeable C3 (also called Cethrin, BA-210 and VX-210) and high dose of } \\
\text { ibuprofen } \\
\text { - GSK-3 inhibitor: lithium }\end{array}$ \\
\hline
\end{tabular}

by a core protein to which the highly sulfated GAG chains are attached (Figure 1). Previous studies suggested that CSPGs acted through non-specific steric interactions, hindering the binding of ECM molecules to their cell surface receptors. Interactions between laminins and their receptor integrins, the growth-promoting adhesion ECM molecules, are crucial for regulating axon growth. CSPGs interrupted the laminin-integrin interactions and attenuated integrin activation (Condic et al., 1999; Afshari et al., 2010). Accordingly, high levels of integrins overcame growth inhibition by CSPGs (Tan et al., 2011).
CSPGs potentiate the functions of some repulsive proteins, such as Sema5A and Sema3A. The GAGs of both CSPGs and heparan sulfate proteoglycans (HSPGs) interacted with the thrombospondin repeats of Sema5A, and CSPG binding could convert Sema5A from an attractive to an inhibitory guidance cue (Kantor et al., 2004). The CS-E motifs of CSPGs, which are enriched in the perineuronal nets, could also interact with Sema3A and contribute to the chemo-repulsive action of this guidance cue (De Wit et al., 2005; Deepa et al., 2006; Kwok et al., 2011). Moreover, the CSPG GAGs could block neuronal growth 
by binding extracellular calcium or its channels, limiting calcium entry into neurons (Hrabetova et al., 2009).

Despite the molecular mechanisms described above, several transmembrane receptors are important in conveying CSPG inhibition of axon growth. Out of three vertebrate homologs (LAR, PTP $\sigma$, and PTP $\delta$ ) in the LAR subfamily, LAR and PTP $\sigma$ have been shown to be neuronal transmembrane receptors essential for mediating growth suppression by CSPGs. CSPG GAG chains bind several positively charged amino acids in the first Ig-like domain of PTP $\sigma$ and LAR and activate these phosphatases (Aricescu et al., 2002; Shen et al., 2009; Fisher et al., 2011). Consistently, a PTP $\sigma$ homolog binds the GAG chains of the HSPG agrin and of collagen XVIII also by its first Ig-like domain, but promotes retinal axon growth (Ledig et al., 1999; Aricescu et al., 2002). Drosophila LAR binds to the HSPGs syndecan and dallylike with high affinity, and thereby regulates synaptic function (Fox and Zinn, 2005; Johnson et al., 2006). A further study demonstrates that HSPGs and CSPGs compete for the same binding site on the first Ig domain of PTP $\sigma$ (Coles et al., 2011). Because HSPG binding triggers PTP $\sigma$ oligomerization and CSPG binding has the opposite effect, the ratio of CSPG:HSPG determines the overall activation status of this receptor. Upregulation of CSPGs blocks PTP $\sigma$ oligomerization, activates this receptor, and thus suppresses neuronal outgrowth. Therefore, PTP $\sigma$ is a bifunctional receptor and its activity depends on the types of ligands bound to it.

PTP $\sigma$ and LAR are important functional receptors for CSPGs in adult mammals. In neuronal cultures, deletion of either PTP $\sigma$ or LAR overcomes growth inhibition by CSPGs, but not by myelin associated inhibitors (Shen et al., 2009; Fisher et al., 2011). Deficiency of either PTP $\sigma$ or LAR significantly increased regrowth of corticospinal tract neurons into the spinal cord several millimeters caudal to the lesion in adult mice with mid-thoracic hemisection injury (Fry et al., 2010; Fisher et al., 2011). Suppressing PTP $\sigma$ or LAR also stimulated regrowth of other spinal cord tracts after spinal cord injury (SCI), including sensory (Shen et al., 2009) and serotonergic axons (Fisher et al., 2011; Lang et al., 2015). Previous studies had reported that regeneration of injured optic nerve and peripheral nerves was enhanced in PTP $\sigma$ knockout mice (McLean et al., 2002; Thompson et al., 2003; Sapieha et al., 2005; Fry et al., 2010). It is not yet known whether PTP $\delta$, the third member in LAR subfamily, also acts as a CSPG receptor to mediate inhibition of axon regeneration. PTP $\delta$ mediated Sema3A-regulated neuronal growth by activating Fyn and Src kinases (Nakamura et al., 2017). Similar to PTP $\sigma$ and LAR, PTP $\delta$ regulates synaptogenesis during development and PTP $\delta$ variants bind with nanomolar affinities to recombinant versions of the HSPG glypican-4 (Ko et al., 2015).

Both LAR and PTP $\sigma$ are important therapeutic targets to promote CNS axon regeneration in adult mammals. Pharmacological blockade of either LAR or PTP $\sigma$ after SCI significantly promotes motor axon regrowth and functional recovery in adult rodents. Systemic treatments with small peptides representing extracellular or intracellular LAR sequences increased the density of serotonergic fibers in spinal cord 5-7 $\mathrm{mm}$ caudal to the lesion in adult mice with T7 dorsal over-hemisection, and also promoted recovery of locomotor function, as determined by multiple behavioral tests (Fisher et al., 2011). Similarly, systemic delivery of a peptide representing the intracellular PTP $\sigma$ sequence dramatically enhanced regrowth of serotonergic axons into the caudal spinal cord, and promoted functional recovery in both locomotor and urinary systems of adult rats with thoracic contusion SCI (Lang et al., 2015).

In lampreys, both LAR and PTP $\sigma$ are expressed selectively in neurons that regenerate poorly post-axotomy (Zhang et al., 2014). Paradoxically, knockdown of PTP $\sigma$ by retrograde delivery of morpholinos from the transection site was followed by inhibition of regeneration and reduction in some measures of locomotor recovery (Rodemer et al., 2020). Presumably, PTP $\sigma$ plays more than one role in the nervous system and the net effect of its knockdown may depend on the balance among its several roles in a given species and environment. In these lamprey experiments, the morpholino also enterred local cells at the lesion site, so the effect of PTP $\sigma$ knockdown might be indirect through actions extrinsic to the reticulospinal neurons. This may highlight the difficulties in translating in vitro studies to partial SCI models and the effects of genetic manipulations to therapies for human SCI.

$\mathrm{NgR} 1$ and NgR3 also act as receptors to mediate growth suppression by CSPGs (Figure 2). The NgR family includes three GPI-anchored receptors (NgR1, NgR2, and NgR3), which have similar structures, including the eight leucine-rich repeats (LRR) flanked by $\mathrm{N}$-terminal and C-terminal LRR-capping domains. NgR1 is the receptor for three myelin associated inhibitors: NogoA, myelin associated glycoprotein (MAG), and oligodendrocyte myelin glycoprotein (OMgp; Fournier et al., 2001, 2002; McGee and Strittmatter, 2003; Liu et al., 2006), while NgR2 binds MAG but not MAP and OMgp (Venkatesh et al., 2005). The ligands that bind NgR3 have not been fully identified. NgR1 and NgR3 interacted with CS and dermatan sulfate chains and functioned as receptors for these proteoglycans (Dickendesher et al., 2012). In this study, deletion of both $\mathrm{NgR} 1$ and $\mathrm{NgR} 3$, but not $\mathrm{NgR} 1$ and $\mathrm{NgR} 2$, overcame CSPG inhibition and promoted regeneration of injured optic nerves in double knockout mice, suggesting that NgR1 and NgR3 mediate some suppression by two completely different groups of inhibitors generated by oligodendrocytes and reactive astrocytes. Furthermore, NgR2 bound versican at the dermo-epidermal junction and this interaction regulated plasticity of peripheral sensory fibers (Bäumer et al., 2014).

\section{NUMEROUS INTRACELLULAR SIGNALS CONVEY CSPG INHIBITION ON NEURONAL GROWTH}

Several intracellular signals have been shown to mediate CSPG inhibition on neuronal growth, including RhoA, Akt, GSK$3 \beta$, protein kinase $\mathrm{C}(\mathrm{PKC})$, and others (Ohtake and $\mathrm{Li}$, 2015). CSPGs, myelin-derived growth inhibitors, and repulsive guidance molecules converge on certain downstream signals, such as activation of RhoA and inactivation of Akt, to regulate 
neuronal growth (Figure 2; Luo, 2000; Etienne-Manneville and Hall, 2002; McGee and Strittmatter, 2003; Mueller et al., 2005; Fu et al., 2007; Dill et al., 2008; Hata et al., 2009). Targeting the converged downstream signals, e.g., inhibiting the Rho signaling pathway, can overcome growth suppression by CSPGs and other inhibitors, thereby promoting axon elongation.

RhoA is important in mediating inhibition of axon growth by CSPGs, myelin-associated inhibitors, and other repulsive guidance cues. In addition to myelin inhibitors (NogoA, MAG, and OMgp; Niederöst et al., 2002) and guidance cues (Sema 3a and Ephrin; Klein, 2004; Gallo, 2006), CSPGs increase activities of RhoA and its effector Rho-associated kinase (ROCK) in neurons (Fournier et al., 2003; Monnier et al., 2003; Jain et al., 2004; Fu et al., 2007; Dill et al., 2008). CSPGs also control growth by targeting local RhoA in the axons because applying CSPGs to the axonal compartment of microfluidic chambers increased intra-axonal RhoA synthesis, while depleting RhoA transcripts in axons promoted their growth in the presence of CSPGs (Walker et al., 2012).

Rho and ROCK act as central regulators of axonal growth by targeting numerous growth-related proteins. Activating the Rho/ROCK pathway phosphorylates several downstream proteins (such as LIM domain kinase 2 and myosin light chain) promotes F-actin disassembly in axonal growth cones (Maekawa et al., 1999), prevents recruitment of microtubules required for axon elongation (Rodriguez et al., 2003), and subsequently induces growth cone collapse by rearranging cytoskeletal proteins (Maekawa et al., 1999; Wu et al., 2005). Collapsin response mediator protein 4 (CRMP4), a microtubule interacting protein, involves CSPG inhibition because CRMP4 deletion promotes growth of neurites on CSPGs in vitro and elongation of sensory axons after spinal cord transection (Nagai et al., 2016). Activation of ROCK by CSPGs and MAG increases the turnover of $\alpha$-tubulin acetyltransferase- $1 \alpha$, which acetylates $\alpha$ tubulin and thus reduces the levels of this acetyltransferase post-transcriptionally (Wong et al., 2018). Therefore, blocking either RhoA or ROCK with inhibitors overcomes growth inhibition by CSPGs and other inhibitors (Borisoff et al., 2003; Mueller et al., 2005) and enhances axon regeneration and functional recovery after CNS axon injury in rodents (Fournier et al., 2003). Moreover, knockdown of RhoA in lamprey reticulospinal neurons by retrogradely-delivered morpholinos inhibited retrograde apoptotic signaling and axon retraction and promoted axon regeneration after SCI (Hu et al., 2017). There also was evidence for transient upregulation of RhoA mRNA in these neurons and for its rapid translocation to the axon tip. After 2 weeks, RhoA expression was reduced selectively in those reticulospinal neurons that did not show caspase activity (Zhang et al., 2018).

CSPGs inactivate PI3K/Akt signals, another intracellular pathway essential for controlling neuronal growth (Ohtake and $\mathrm{Li}, 2015)$. In neuronal cultures, CSPG stimulation reduces the levels of phosphorylated Akt at Ser473 and S6 kinase (Dill et al., 2008; Fisher et al., 2011; Silver et al., 2014; Ohtake et al., 2016). Inactivation of Akt is likely to suppress signaling by mTOR, an upstream activator of protein synthesis involved in axonal regeneration (Park et al., 2008, 2010; Liu et al., 2010).
Accordingly, deleting PTEN and degrading CSPGs prevent mTOR inhibition and enhance axon regrowth after CNS injury (Lee et al., 2014). Application of CSPGs also enhances the levels of 4E-BP1 (Walker et al., 2012), a negative signal along the PI3K/Akt pathway (Yang et al., 2014).

PKC also appears to be a downstream signal to mediate CSPG action. CSPGs and myelin-associated inhibitors activated PKC, while PKC blockade overcame the growth suppression and promoted regeneration of dorsal column sensory axons in adult rats with SCI (Sivasankaran et al., 2004). However, application of CS-E tetrasaccharide, one of the CSPG GAG chains, enhanced neurite outgrowth, and inhibition of PKC with bisindolylmaleimide II or digestion of GAGs with ChABC abolished the increased axon growth (Sotogaku et al., 2007). Thus, further studies are required to dissect the role of PKC in mediating CSPG action.

CSPGs also activate epidermal growth factor receptor (EGFR) pathways, while suppressing the kinase activity of EGFR, or its downstream mitogen-activated protein kinase (MAPK), reverses inhibition of axon growth by CSPGs (Koprivica et al., 2005; Kaneko et al., 2007). Inhibition of ErbB1, an EGFR, by either pharmacological or genetic approach, promotes neuronal growth in the presence of CSPG, CNS myelin, or fibrinogen (Leinster et al., 2013). Moreover, myosin II, an ATP-dependent motor protein, probably mediates CSPG inhibition on axonal growth (Hur et al., 2011; Yu et al., 2012). CSPGs increase phosphorylation of nonmuscle myosin II regulatory light chains, while pharmacological or genetic inhibition of myosin II promotes axon growth in vitro on inhibitory substrates including CSPGs and axon regeneration after optic nerve injury (Wang et al., 2020).

Repulsive guidance molecule A (RGMa), a GPI-linked glycoprotein, inhibits axon growth by interacting with its neuronal receptor neogenin, but it also promotes reactive astrogliosis and glial scar formation by activating the TGF $\beta 1$ Smad2/3 signaling pathway and preventing neurological functional recovery after stroke (Zhang et al., 2018). Consistently, treatments with RGMa antibodies promoted axon regeneration and functional recovery in adult rodents with SCI and also showed a trend toward reducing CSPG expression around the lesion (Hata et al., 2006; Mothe et al., 2017). In lampreys, neogenin mRNA is expressed selectively in poorly regenerating reticulospinal neurons, while RGM is downregulated in cells near a spinal cord transection, possibly increasing the ability of axons to grow through the lesion (Shifman et al., 2009).

\section{TWO RPTPS USE BOTH CONVERGENT AND DIVERGENT SIGNALING PATHWAYS TO CONVEY CSPG INHIBITION IN NEURONS}

CSPGs may suppress neuronal growth by sterically hindering growth-promoting adhesion molecules and facilitating inhibition by chemo-repulsive molecules (Condic et al., 1999; Kantor et al., 2004; Tan et al., 2011), but some receptors are important in transmitting CSPG inhibition, including PTP $\sigma, \mathrm{LAR}, \mathrm{NgR} 1$, 
and NgR3 (Shen et al., 2009; Fisher et al., 2011; Dickendesher et al., 2012; Lang et al., 2015; Xu et al., 2015). Among them, PTP $\sigma$ and LAR, two members in the LAR subfamily, bind CSPGs with high affinity and mediate their suppression of neuronal growth. Using combined gain-of-function and loss-of function approaches (Ohtake et al., 2016), a group recently demonstrates that LAR and PTPo use several common signaling pathways, including RhoA, Akt, Erk, and MAP1B (Ohtake et al., 2016). But they also transmit CSPG effects with distinct signals, including the use of CRMP2, adenomatous polyposis coli (APC), S6 kinase and CREB by PTP $\sigma$, and the use of cofilin, $\mathrm{PKC} \zeta$, and liver kinase B1 (LKB1) by LAR (Figure 2). Combined deficiencies of both receptors promoted additional neurite outgrowth by adult neurons in the presence of CSPGs in vitro.

RhoA signaling mediates functions of both LAR and PTP $\sigma$ in neurons. Application of CSPGs significantly increases the levels of active RhoA in N2A cells (a neuronal cell line) transfected with either PTP $\sigma$ or LAR, indicating that interactions between CSPGs and each of the PTPs separately activate RhoA (Ohtake et al., 2016). Consistently, administration of CSPGs increased the levels of active RhoA in cultured cerebellar granule neurons (CGNs) derived from wildtype (WT) mice, but not from either $\mathrm{PTP} \sigma-/-$ or $\mathrm{LAR}-/-$ mice. As a downstream mediator of RhoA, ROCK can phosphorylate and activate LIM kinase, which in turn phosphorylates and inactivates cofilin (Maekawa et al., 1999; Zhang et al., 2006). Actin depolymerizing factor (ADF) and cofilin are highly expressed in the actin disassembly region of neuronal growth cones and play a critical role in regulating actin dynamics and axon growth. Upregulating ADF/cofilin increased neurite length by disassembling actin filaments and promoting microtubulebased extension. ADF/cofilin also controlled actin turnover to sustain regeneration of adult rodent axons after SCI by disarranging actin (Tedeschi et al., 2019). Levels of p-cofilin were dramatically elevated in LAR-transfected but not PTP $\sigma$ transfected N2A cells after incubation with CSPGs, suggesting that CSPG-LAR interactions increase cofilin phosphorylation and inhibit axon elongation by reducing actin disassembly. Accordingly, ROCK inhibitors diminished p-cofilin levels in CSPG-stimulated PC12 cells (Gopalakrishnan et al., 2008). CSPG stimulation also boosts the levels of p-cofilin in WT, but not LAR-/- CGNs. Therefore, inactivating cofilin by phosphorylation probably mediates the inhibition by CSPGLAR, but not CSPG-PTP $\sigma$.

Several signals in the mTOR pathway convey the functions of both LAR and PTP $\sigma$ although they mostly mediate the actions of PTPб (Ohtake et al., 2016). CSPG stimulation reduced the levels of p-Akt in N2A cells transfected with either PTP $\sigma$ or LAR, and in WT CGNs, but not in PTP $\sigma-/-$ or LAR-/CGNs, indicating that Akt mediates functions of both receptors upon CSPG application. Increased Akt activity has also been reported in PTPo-/- neurons (Sapieha et al., 2005). Activation (phosphorylation) of S6 kinase, a downstream effector of mTOR, was reduced by CSPGs in a neuronal cell line overexpressing PTP $\sigma$, but not LAR, and in WT, but not PTP $\sigma$-deleted CGNs. Thus, S6 kinase mediates the interactions between CSPGs and PTP $\sigma$, but not LAR. The levels of pS6 have been correlated with increased translation of many mRNA transcripts and cell growth (Park et al., 2008).

Another mTOR downstream signal, p-4E-BP1(Thr37/46, inactive), plays a modest role in regulating CSPG-receptor interactions (Ohtake et al., 2016). Phosphorylation of CRMP2, a signal downstream of both the Akt and Rho pathways, contributes to axon growth inhibition produced by CSPG-PTP $\sigma$ interactions. Inactivation of CRMP2 by phosphorylation induces axon growth cone collapse (Arimura et al., 2005; Uchida et al., 2005; Petratos et al., 2008; Wakatsuki et al., 2011). Furthermore, APC and MAP1B, two substrates of GSK-3 $\beta$ in the mTOR pathway, mediate functions of PTP $\sigma$ (Figure 2), but APC is not involved in LAR action, and MAP1B appears to mediate the action of LAR to a greater degree than that of PTP $\sigma$ (Ohtake et al., 2016).

Erk mediates actions of PTP $\sigma$ and LAR by distinct downstream signaling pathways (Ohtake et al., 2016). Evaluation of Erk activity by measuring p-p44/42 MAPK (Erk1/2) at Thr202/Tyr204 demonstrates that CSPGs greatly reduce its levels in neurons derived from WT mice, but not PTP $\sigma$ - or LAR-deleted mice. CSPGs and myelin-associated inhibitors were previously linked to Erk signaling (Stern and Knöll, 2014), and treatment with nerve growth factor, a signal upstream of Erk, promoted neuronal growth on CSPGs (Zhou et al., 2006). Downstream of Erk, CREB regulates the interactions between CSPGs and PTP $\sigma$. In contrast, the $90 \mathrm{kDa}$ ribosomal S6 kinases (p90RSKs), which are characterized by two non-identical functional kinase domains and a C-terminal docking site for Erks (Fisher and Blenis, 1996; Smith et al., 1999), play only a minor role in mediating functions of PTP $\sigma$ and LAR.

LKB1 signaling mediates CSPG-LAR, but not CSPGPTP $\sigma$, interactions (Ohtake et al., 2016). Erk and S6 kinase phosphorylate multiple substrates, including LKB1 at Ser325 and Ser428 (Ser431 in the mouse), which is critical for subsequent activation of AMP-activated protein kinase (AMPK; Zheng et al., 2009) and for control of axon development (Barnes et al., 2007; Huang et al., 2014). Measurement of p-LKB1 indicated the significant role for LKB1 in mediating LAR, but not $\mathrm{PTP} \sigma$ action. PKC $\zeta$, a member of the atypical PKC subfamily, phosphorylates LKB1 at Ser-428/431 and mediates AMPK activation in endothelial cells (Shifman et al., 2009; Xu et al., 2015). In neurons, the PKC $\zeta$ isoform contributes to the action of LAR in response to CSPG application, probably by regulating LKB1 activity (Ohtake et al., 2016). Overexpression of LKB1 in mature neurons promoted dramatic axon regeneration in adult mice with SCI (Ohtake et al., 2019). NG2, a non-lectican CSPG, also activates $\mathrm{PKC} \zeta$ and $\mathrm{Cdc} 42$ and increases association of $\mathrm{PKC} \zeta$ with Par6 (Lee et al., 2013). Although the cAMP-dependent PKA may activate LKB1 by phosphorylating it at S431, and thereby promote axon differentiation during development (Collins et al., 2000; Barnes et al., 2007; Shelly et al., 2007), PKA plays only a minimal role in mediating actions of LAR or PTP $\sigma$ (Ohtake et al., 2016). Neither does the conventional PKC mediate the functions of either LAR or PTP $\sigma$ in neurons.

Several other proteins have been reported to function as signals downstream of PTP $\sigma$. NDPK2 (nucleoside diphosphate kinase 2) interacts with PTP $\sigma$ and NDPK2 knockdown in cortical 
neurons overcomes inhibition by CSPGs (Hamasaki et al., 2016). Ezrin, a linker protein between the plasma membrane and actin cytoskeleton, is a substrate of PTP $\sigma$ and regulates migration and organization of cells by altering adhesion of their surface structures (Doody et al., 2015). N-cadherin and $\beta$-catenin are also PTP $\sigma$ substrates and may regulate axon growth downstream of PTP $\sigma$ (Siu et al., 2007). Moreover, CSPG-PTP $\sigma$ interactions may regulate autophagic flux at the axon growth cone by inhibiting autophagosome-lysosomal fusion step (Tran et al., 2020).

Together, LAR and PTP $\sigma$ share certain signaling pathways but also employ distinct signals to covey CSPG effects on neurons, suggesting that targeting both PTP receptors have additive effects in overcoming CSPG inhibition of axon growth. Indeed, deleting either of these receptors enhanced neurite growth in adult neurons cultured on CSPGs, but deleting both displayed greater axon growth in vitro, indicating synergy between two RPTPs in mediating CSPG function (Ohtake et al., 2016).

\section{CSPG DOWNSTREAM SIGNALS ARE THERAPEUTIC TARGETS FOR CNS INJURIES}

Currently, there are no FDA approved pharmacological therapies to recover motor and sensory functions in patients with CNS axon injuries. Overcoming strong suppression by glial scars and CSPG-mediated growth inhibition is a major target for therapeutic intervention after CNS injuries. Previously, the main in vivo method to overcome inhibition by CSPGs was enzymatic digestion with locally applied $\mathrm{ChABC}$, but some disadvantages (such as the short duration of enzymatic activity at $37^{\circ} \mathrm{C}$ and potential immune responses after repeated applications) may prevent using this bacterial enzyme as a therapeutic option for patients (Sharma et al., 2012; Ohtake and Li, 2015). Better understanding of signaling pathways, including identification of CSPG receptors, has led to new approaches for overcoming CSPG-mediated inhibition. Systemic applications of selective antagonists for CSPG receptors have promoted remarkable axon regrowth and functional recovery of motor and autonomic systems after SCI (Fisher et al., 2011; Lang et al., 2015; Urban et al., 2019a,b). Diverse axon growth inhibitors from scar tissues and myelin debris suppress neuronal growth through converging downstream pathways, suggesting the alternative approaches to overcome inhibition of axon growth in the CNS. Some compounds that regulate the activities of intracellular signals, including inhibitors of signaling by Rho and GSK-3 $\beta$, are promising for promoting CNS axon regeneration and recovery in adult mammals (Meijer et al., 2004; Mueller et al., 2005; McKerracher and Higuchi, 2006; Fehlings et al., 2011).

Inhibitors of RhoA and ROCK have been reported to promote cell survival, axon regrowth, and functional recovery after SCI, stroke, and other CNS injuries (Kubo and Yamashita, 2007; Chong et al., 2017; Sladojevic et al., 2017). After CNS lesions, CSPGs and other inhibitors activate Rho and its downstream ROCK, which cause apoptotic cell loss, growth cone collapse, and axon regeneration failure. The bacterial C3 transferase and its derivatives have been frequently used as selective inhibitors of Rho by ADP-ribosylating the Rho effector domain and blocking Rho function. C3 treatment prevents cell loss and promotes axon regeneration after SCI and optic nerve crush in rodents (Lehmann et al., 1999; Dergham et al., 2002; Dubreuil et al., 2003). In SCI rodents, a modified C3 that is cell-permeable (also called Cethrin, BA-210, and VX-210) and a recombinant fusion protein containing $\mathrm{C} 3$ inactivated RhoA in the lesioned spinal cord reduced secondary tissue damage and glial scarring, stimulated axon regeneration and functional recovery, even when applied 16 days after injury (Lord-Fontaine et al., 2008). Other Rho inhibitors that have been used to promote CNS regeneration include C3-peptides, siRNA, and ibuprofen (Fu et al., 2007; Boato et al., 2010; Dill et al., 2010; Gwak et al., 2017). Furthermore, several ROCK inhibitors have been developed, including Fasudil and its derivatives (hydroxyfasudil and dimethylfusudil), Y-27632 and Y-39983. They also enhanced axon regrowth and provided neuroprotection in different models of neurological disorders (Kubo and Yamashita, 2007; Fujita and Yamashita, 2014).

Because preclinical studies showed promising results on the Rho inhibitor C3, a phase I/IIa clinical trial of VX-210 had been completed to test its potential to enhance motor function in patients with acute SCI (NCT00500812; Fehlings et al., 2011; McKerracher and Anderson, 2013). In this trial, 48 acute traumatic cervical and thoracic SCI patients received a single dose of VX-210 (range: $0.3-9.0 \mathrm{mg}$ ) applied to the spinal cord dura mater during decompression surgery within the first 7 days after injury. The results suggested the tolerability of the treatment and improvement in motor strength in patients with cervical SCI compared to its natural course. The recovery trajectory of thoracic SCI cases was similar to that in natural history studies (Fehlings et al., 2011). Because of the promising results of phase I/IIa clinical trial, VX-210 was moved to a phase IIb/III SPRING (SCI Rho inhibition investigation) trial for acute traumatic cervical SCI (NCT02669849). The major goal of this randomized, double-blind, placebo-controlled trial was to evaluate its safety and efficacy in promoting functional recovery by Rho inhibition (Fehlings et al., 2018). However, this trial was terminated by Vertex probably because of lack of efficacy after an interim analysis.

A subset of non-steroidal anti-inflammatory drugs (NSAIDs), including ibuprofen, indomethacin, and sulindac sulfide, inhibit Rho activity independently of their classical function as the inhibitors of cyclooxygenases and promote axon regrowth and functional recovery after SCI in rodents (Zhou et al., 2003; Fu et al., 2007; Wang et al., 2009). PPAR $\gamma$ activation contributes to the ibuprofen-mediated Rho inhibition in neurons (Dill et al., 2010). Meta-analysis of multiple preclinical studies on the effects of Rho-inhibiting NSAIDs suggested a moderate effect on motor recovery after ibuprofen or indomethacin treatment (Watzlawick et al., 2014). Because NSAIDs are widely used clinically for relieving pain and treating various disorders, it would be especially attractive to test Rho-inhibiting NSAIDS, including ibuprofen, as treatments for CNS axonal injuries. A phase I clinical SCISSOR (SCI study on small molecule-derived Rho inhibition) trial has been initiated to treat acute SCI with high-dose ibuprofen (NCT02096913; Kopp et al., 2016). The 
key inclusion criteria include acute traumatic motor-complete SCI (classified as AIS A or AIS B) with lesions at the levels of C4-Th4. The major goal of this trial is to evaluate the safety, feasibility, and pharmacokinetics of ibuprofen when used at the high dose of 2,400 mg per day. Preclinical studies showed potent Rho inhibition by ibuprofen when applied at high doses (50-70 mg/Kg body weight; Zhou et al., 2003; Fu et al., 2007; Wang et al., 2009).

Treatments with GSK-3 $\beta$ inhibitors, including the clinical drug lithium, have overcome the growth suppression of CNS inhibitory substrates and promoted axonal regeneration and functional recovery in adult rodents with SCI (Dill et al., 2008). As one of the downstream signals in the mTOR pathway, GSK$3 \beta$ mediates CSPG action and plays a critical role in regulating axon genesis and elongation. Thus, inhibiting GSK-3 $\beta$, possibly with lithium, which is commonly used to treat bipolar illness, is an interesting potential therapeutic approach for promoting axon regrowth and functional recovery after CNS injuries (Dill et al., 2008; Ohtake et al., 2016). Lithium also enhanced proliferation and neuronal differentiation of neural progenitor cells in the spinal cord of adult rats (Su et al., 2007).

A phase I clinical trial was completed to evaluate the safety and pharmacokinetics of lithium in chronic SCI patients (NCT00431171). This trial suggests that lithium is safe for treating chronic SCI patients (Wong et al., 2011). A randomized, double-blind phase II clinical trial was performed to evaluate its efficacy for treating chronic SCI patients (NCT00750061; Yang et al., 2012). Lithium was effective for reducing neuropathic pain in chronic SCI but did not improve the neurological outcomes of patients. Further clinical trials with combined strategies, including transplanting umbilical cord blood-derived mononuclear cells plus oral lithium or methylprednisolone followed by locomotor training, improved both motor and autonomic functions in some SCI patients (NCT01046786 and NCT01354483; Zhu et al., 2016), but the exact role of lithium was less clear in these trials.

\section{PROSPECTIVE}

Achieving functional regeneration after CNS axonal injury is a challenging topic in neuroscience research. Although a developmentally determined reduction in the intrinsic capacity of mature neurons for growth contributes to CNS regeneration failure, the scar tissue and its associated inhibitors form potent physical and chemical barriers to axon elongation after CNS injury. Therefore, it is critical to design effective regenerative strategies that target the inhibitory CNS environment. Early after injury, reactive astrocytes exert positive effects in promoting tissue repair and axon regrowth by limiting tissue damage, preventing extension of the injury into adjacent areas, and generating many ECM components such as fibronectin and laminin that have growth-promoting properties (Bush et al., 1999; Faulkner et al., 2004; Anderson et al., 2016).

In the past decade, researchers have made significant progress in further understanding the functions of reactive scar tissue, including identification of several functional receptors for scar-associated inhibitors and dissection of intracellular signals downstream of these inhibitors. It would be valuable to identify additional receptors of CSPGs and to determine whether different CSPGs and HSPGs have binding preferences to the diverse receptors recognized. Although CSPGs, HSPGs, Ezrin, and nucleoside diphosphate kinase 2 have been recognized as the ligands of PTP $\sigma$ and/or LAR, additional substrates might to be identified.

CSPGs and other extracellular molecules (such as myelinassociated inhibitors, guidance cues, and neurotrophins) share certain intracellular signals (e.g., RhoA, Akt, and Erk) that mediate neuronal growth. It would be valuable to determine whether specific interventions of the identified downstream signals alter the responses of individual extracellular molecules and their corresponding receptors. As outlined in Figure 2, PTP $\sigma$ and LAR mediate CSPG actions by both convergent and divergent signaling pathways, but it is critical to dissect additional pathways, their molecular links to transmembrane receptors and cytoskeletal structures, and the potential interactions among these intracellular signals. A better understanding of the molecular pathways for axon growth regulators should facilitate the design of effective regenerative and reparative strategies to treat CNS injuries.

Overcoming strong suppression of axon growth by CSPGs and glial scars is a main target for therapeutic intervention after CNS injuries. Many researchers have focused on digestion of the CSPG GAG side chains with local application of ChABC. Because several disadvantages may prevent using this bacterial enzyme as a therapeutic option for patients, alternative approaches to neutralizing growth inhibition by glial scars are needed, including targeting CSPG receptors and their downstream signals. Indeed, intervening in the convergent signals is promising because they may convey actions of multiple extracellular molecules, including both repulsive and attractive factors for neuronal growth. Several drugs that block Rho or GSK-3 $\beta$ were moved to clinical trials for treating CNS axonal injuries but have not yet borne fruit. Because multiple factors contribute to CNS repair failure, combined strategies, such as effective neuroprotectants to prevent cell loss, regenerative approaches to target both neuron-intrinsic and extrinsic factors, cell/biomaterial transplants to bridge rostral and caudal neural tissues, and task-specific rehabilitative training to enhance plasticity of neural circuits, may be required to further promote neural regeneration and functional recovery after CNS injuries.

\section{AUTHOR CONTRIBUTIONS}

All authors listed have made a substantial, direct and intellectual contribution to the work, and approved it for publication.

\section{FUNDING}

This work was supported by research grants to SL from NIH (R01NS105961, 1R01NS079432 and 1R01EY024575) and from Shriners Research Foundation (SHC-85100, SHC-86200-PHI16 and 85112-PHI-18) and to MS from NIH (R01 NS092876 and R01 NS097846) and from Shriners Research Foundation (SHC85220 and SHC-85101). 


\section{REFERENCES}

Afshari, F. T., Kwok, J. C., White, L., and Fawcett, J. W. (2010). Schwann cell migration is integrin-dependent and inhibited by astrocyte-produced aggrecan. Glia 58, 857-869. doi: 10.1002/glia.20970

Anderson, M. A., Burda, J. E., Ren, Y., Ao, Y., O’Shea, T. M., Kawaguchi, R., et al. (2016). Astrocyte scar formation aids central nervous system axon regeneration. Nature 532, 195-200. doi: 10.1038/nature17623

Aricescu, A. R., McKinnell, I. W., Halfter, W., and Stoker, A. W. (2002). Heparan sulfate proteoglycans are ligands for receptor protein tyrosine phosphatase sigma. Mol. Cell. Biol. 22, 1881-1892. doi: 10.1128/mcb.22.6.1881-1892.2002

Arimura, N., Ménager, C., Kawano, Y., Yoshimura, T., Kawabata, S., Hattori, A., et al. (2005). Phosphorylation by Rho kinase regulates CRMP-2 activity in growth cones. Mol. Cell. Biol. 25, 9973-9984. doi: 10.1128/mcb.25.22.99739984.2005

Bandtlow, C. E., and Zimmermann, D. R. (2000). Proteoglycans in the developing brain: new conceptual insights for old proteins. Physiol. Rev. 80, 1267-1290. doi: 10.1152/physrev.2000.80.4.1267

Barnes, A. P., Lilley, B. N., Pan, Y. A., Plummer, L. J., Powell, A. W., Raines, A. N., et al. (2007). LKB1 and SAD kinases define a pathway required for the polarization of cortical neurons. Cell 129, 549-563. doi: 10.1016/j.cell.2007. 03.025

Bäumer, B. E., Kurz, A., Borrie, S. C., Sickinger, S., Dours-Zimmermann, M. T., Zimmermann, D. R., et al. (2014). Nogo receptor homolog NgR2 expressed in sensory DRG neurons controls epidermal innervation by interaction with Versican. J. Neurosci. 34, 1633-1646. doi: 10.1523/JNEUROSCI.3094-13.2014

Blesch, A., and Tuszynski, M. H. (2009). Spinal cord injury: plasticity, regeneration and the challenge of translational drug development. Trends Neurosci. 32, 41-47. doi: 10.1016/j.tins.2008.09.008

Boato, F., Hendrix, S., Huelsenbeck, S. C., Hofmann, F., Grosse, G., Djalali, S., et al. (2010). C3 peptide enhances recovery from spinal cord injury by improved regenerative growth of descending fiber tracts. J. Cell Sci. 123, 1652-1662. doi: $10.1242 /$ jcs. 066050

Borisoff, J. F., Chan, C. C., Hiebert, G. W., Oschipok, L., Robertson, G. S., Zamboni, R., et al. (2003). Suppression of Rho-kinase activity promotes axonal growth on inhibitory CNS substrates. Mol. Cell. Neurosci. 22, 405-416. doi: 10.1016/s1044-7431(02)00032-5

Bradbury, E. J., Moon, L. D., Popat, R. J., King, V. R., Bennett, G. S., Patel, P. N., et al. (2002). Chondroitinase $A B C$ promotes functional recovery after spinal cord injury. Nature 416, 636-640. doi: 10.1038/416636a

Brown, J. M., Xia, J., Zhuang, B., Cho, K. S., Rogers, C. J., Gama, C. I., et al. (2012). A sulfated carbohydrate epitope inhibits axon regeneration after injury. Proc. Natl. Acad. Sci. U S A 109, 4768-4773. doi: 10.1073/pnas.1121318109

Busch, S. A., and Silver, J. (2007). The role of extracellular matrix in CNS regeneration. Curr. Opin. Neurobiol. 17, 120-127. doi: 10.1016/j.conb.2006. 09.004

Bush, T. G., Puvanachandra, N., Horner, C. H., Polito, A., Ostenfeld, T., Svendsen, C. N., et al. (1999). Leukocyte infiltration, neuronal degeneration and neurite outgrowth after ablation of scar-forming, reactive astrocytes in adult transgenic mice. Neuron 23, 297-308. doi: 10.1016/s0896-6273(00) 80781-3

Chong, C. M., Ai, N., and Lee, S. M. (2017). ROCK in CNS: different roles of isoforms and therapeutic target for neurodegenerative disorders. Curr. Drug Targets 18, 455-462. doi: 10.2174/1389450117666160401123825

Coles, C. H., Shen, Y., Tenney, A. P., Siebold, C., Sutton, G. C., Lu, W., et al. (2011). Proteoglycan-specific molecular switch for RPTPsigma clustering and neuronal extension. Science 332, 484-488. doi: 10.1126/science.1200840

Collins, S. P., Reoma, J. L., Gamm, D. M., and Uhler, M. D. (2000). LKB1, a novel serine/threonine protein kinase and potential tumour suppressor, is phosphorylated by cAMP-dependent protein kinase (PKA) and prenylated in vivo. Biochem. J. 345, 673-680. doi: 10.1042/bj3450673

Condic, M. L., Snow, D. M., and Letourneau, P. C. (1999). Embryonic neurons adapt to the inhibitory proteoglycan aggrecan by increasing integrin expression. J. Neurosci. 19, 10036-10043. doi: 10.1523/JNEUROSCI.19-2210036.1999

Davies, S. J., Fitch, M. T., Memberg, S. P., Hall, A. K., Raisman, G., and Silver, J. (1997). Regeneration of adult axons in white matter tracts of the central nervous system. Nature 390, 680-683. doi: 10.1038/37776
De Wit, J., De Winter, F., Klooster, J., and Verhaagen, J. (2005). Semaphorin 3A displays a punctate distribution on the surface of neuronal cells and interacts with proteoglycans in the extracellular matrix. Mol. Cell. Neurosci. 29, 40-55. doi: 10.1016/j.mcn.2004.12.009

Deepa, S. S., Carulli, D., Galtrey, C., Rhodes, K., Fukuda, J., Mikami, T., et al. (2006). Composition of perineuronal net extracellular matrix in rat brain: a different disaccharide composition for the net-associated proteoglycans. J. Biol. Chem. 281, 17789-17800. doi: 10.1074/jbc.m600544200

Dergham, P., Ellezam, B., Essagian, C., Avedissian, H., Lubell, W. D., and McKerracher, L. (2002). Rho signaling pathway targeted to promote spinal cord repair. J. Neurosci. 22, 6570-6577. doi: 10.1523/JNEUROSCI.22-15-06570.2002

Dickendesher, T. L., Baldwin, K. T., Mironova, Y. A., Koriyama, Y., Raiker, S. J., Askew, K. L., et al. (2012). NgR1 and NgR3 are receptors for chondroitin sulfate proteoglycans. Nat. Neurosci. 15, 703-712. doi: 10.1038/nn.3070

Dill, J., Patel, A. R., Yang, X. L., Bachoo, R., Powell, C. M., and Li, S. (2010). A molecular mechanism for ibuprofen-mediated RhoA inhibition in neurons. J. Neurosci. 30, 963-972. doi: 10.1523/JNEUROSCI.5045-09.2010

Dill, J., Wang, H., Zhou, F. Q., and Li, S. (2008). Inactivation of glycogen synthase kinase-3 promotes axonal growth and recovery in the CNS. J. Neurosci. 28 , 8914-8928. doi: 10.1523/JNEUROSCI.1178-08.2008

Doody, K. M., Stanford, S. M., Sacchetti, C., Svensson, M. N., Coles, C. H., Mitakidis, N., et al. (2015). Targeting phosphatase-dependent proteoglycan switch for rheumatoid arthritis therapy. Sci. Transl. Med. 7:288ra76. doi: 10.1126/scitranslmed.aaa4616

Dubreuil, C. I., Winton, M. J., and McKerracher, L. (2003). Rho activation patterns after spinal cord injury and the role of activated Rho in apoptosis in the central nervous system. J. Cell Biol. 162, 233-243. doi: 10.1083/jcb.200301080

Dyck, S. M., and Karimi-Abdolrezaee, S. (2015). Chondroitin sulfate proteoglycans: key modulators in the developing and pathologic central nervous system. Exp. Neurol. 269, 169-187. doi: 10.1016/j.expneurol.2015. 04.006

Etienne-Manneville, S., and Hall, A. (2002). Rho GTPases in cell biology. Nature 420, 629-635. doi: 10.1038/nature01148

Faulkner, J. R., Herrmann, J. E., Woo, M. J., Tansey, K. E., Doan, N. B., and Sofroniew, M. V. (2004). Reactive astrocytes protect tissue and preserve function after spinal cord injury. J. Neurosci. 24, 2143-2155. doi: 10.1523/JNEUROSCI.3547-03.2004

Fehlings, M. G., Kim, K. D., Aarabi, B., Rizzo, M., Bond, L. M., McKerracher, L., et al. (2018). Rho inhibitor VX-210 in acute traumatic subaxial cervical spinal cord injury: design of the SPinal cord injury rho INhibition investiGation (SPRING) clinical trial. J. Neurotrauma 35, 1049-1056. doi: 10.1089/neu. 2017.5434

Fehlings, M. G., Theodore, N., Harrop, J., Maurais, G., Kuntz, C., Shaffrey, C. I., et al. (2011). A phase I/IIa clinical trial of a recombinant Rho protein antagonist in acute spinal cord injury. J. Neurotrauma 28, 787-796. doi: 10.1089/neu. 2011.1765

Fisher, D., Xing, B., Dill, J., Li, H., Hoang, H. H., Zhao, Z., et al. (2011). Leukocyte common antigen-related phosphatase is a functional receptor for chondroitin sulfate proteoglycan axon growth inhibitors. J. Neurosci. 31, 14051-14066. doi: 10.1523/JNEUROSCI.1737-11.2011

Fisher, T. L., and Blenis, J. (1996). Evidence for two catalytically active kinase domains in pp90rsk. Mol. Cell. Biol. 16, 1212-1219. doi: 10.1128/mcb.16.3.1212

Fournier, A. E., GrandPre, T., and Strittmatter, S. M. (2001). Identification of a receptor mediating Nogo-66 inhibition of axonal regeneration. Nature 409, 341-346. doi: 10.1038/35053072

Fournier, A. E., GrandPré, T., Gould, G., Wang, X., and Strittmatter, S. M. (2002). Nogo and the Nogo-66 receptor. Prog. Brain Res. 137, 361-369. doi: 10.1016/s0079-6123(02)37027-4

Fournier, A. E., Takizawa, B. T., and Strittmatter, S. M. (2003). Rho kinase inhibition enhances axonal regeneration in the injured CNS. J. Neurosci. 23, 1416-1423. doi: 10.1523/JNEUROSCI.23-04-01416.2003

Fox, A. N., and Zinn, K. (2005). The heparan sulfate proteoglycan syndecan is an in vivo ligand for the Drosophila LAR receptor tyrosine phosphatase. Curr. Biol. 15, 1701-1711. doi: 10.1016/j.cub.2005.08.035

Fry, E. J., Chagnon, M. J., López-Vales, R., Tremblay, M. L., and David, S. (2010). Corticospinal tract regeneration after spinal cord injury in receptor protein tyrosine phosphatase sigma deficient mice. Glia 58, 423-433. doi: 10.1002/glia. 20934 
Fu, Q., Hue, J., and Li, S. (2007). Nonsteroidal anti-inflammatory drugs promote axon regeneration via RhoA inhibition. J. Neurosci. 27, 4154-4164. doi: 10.1523/JNEUROSCI.4353-06.2007

Fujita, Y., and Yamashita, T. (2014). Axon growth inhibition by RhoA/ROCK in the central nervous system. Front. Neurosci. 8:338. doi: 10.3389/fnins.2014. 00338

Gallo, G. (2006). RhoA-kinase coordinates F-actin organization and myosin II activity during semaphorin-3A-induced axon retraction. J. Cell Sci. 119, 3413-3423. doi: $10.1242 /$ jcs. 03084

Galtrey, C. M., and Fawcett, J. W. (2007). The role of chondroitin sulfate proteoglycans in regeneration and plasticity in the central nervous system. Brain Res. Rev. 54, 1-18. doi: 10.1016/j.brainresrev.2006.09.006

Gilbert, R. J., McKeon, R. J., Darr, A., Calabro, A., Hascall, V. C., and Bellamkonda, R. V. (2005). CS-4,6 is differentially upregulated in glial scar and is a potent inhibitor of neurite extension. Mol. Cell. Neurosci. 29, 545-558. doi: $10.1016 / \mathrm{j} . \mathrm{mcn} .2005 .04 .006$

Gopalakrishnan, S. M., Teusch, N., Imhof, C., Bakker, M. H., Schurdak, M., Burns, D. J., et al. (2008). Role of Rho kinase pathway in chondroitin sulfate proteoglycan-mediated inhibition of neurite outgrowth in PC12 cells. J. Neurosci. Res. 86, 2214-2226. doi: 10.1002/jnr.21671

Gwak, S. J., Macks, C., Jeong, D. U., Kindy, M., Lynn, M., Webb, K., et al. (2017). RhoA knockdown by cationic amphiphilic copolymer/siRhoA polyplexes enhances axonal regeneration in rat spinal cord injury model. Biomaterials 121, 155-166. doi: 10.1016/j.biomaterials.2017.01.003

Hamasaki, H., Fujitani, M., and Yamashita, T. (2016). NME2 associates with PTPsigma to transduce signals from chondroitin sulfate proteoglycans. Biochem. Biophys. Res. Commun. 471, 522-527. doi: 10.1016/j.bbrc.2016. 02.042

Hata, K., Fujitani, M., Yasuda, Y., Doya, H., Saito, T., Yamagishi, S., et al. (2006). RGMa inhibition promotes axonal growth and recovery after spinal cord injury. J. Cell Biol. 173, 47-58. doi: 10.1083/jcb.200508143

Hata, K., Kaibuchi, K., Inagaki, S., and Yamashita, T. (2009). Unc5B associates with LARG to mediate the action of repulsive guidance molecule. J. Cell Biol. 184, 737-750. doi: $10.1083 /$ jcb. 200807029

Hrabetova, S., Masri, D., Tao, L., Xiao, F., and Nicholson, C. (2009). Calcium diffusion enhanced after cleavage of negatively charged components of brain extracellular matrix by chondroitinase ABC. J. Physiol. 587, 4029-4049. doi: 10.1113/jphysiol.2009.170092

Hu, J., Zhang, G., Rodemer, W., Jin, L. Q., Shifman, M., and Selzer, M. E. (2017). The role of RhoA in retrograde neuronal death and axon regeneration after spinal cord injury. Neurobiol. Dis. 98, 25-35. doi: 10.1016/j.nbd.2016.11.006

Huang, W., She, L., Chang, X. Y., Yang, R. R., Wang, L., Ji, H. B., et al. (2014). Protein kinase LKB1 regulates polarized dendrite formation of adult hippocampal newborn neurons. Proc. Natl. Acad. Sci. U S A 111, 469-474. doi: 10.1073/pnas.1321454111

Hur, E. M., Yang, I. H., Kim, D. H., Byun, J., Saijilafu, Xu, W. L., et al. (2011). Engineering neuronal growth cones to promote axon regeneration over inhibitory molecules. Proc. Natl. Acad. Sci. U S A 108, 5057-5062. doi: 10.1073/pnas.1011258108

Jain, A., Brady-Kalnay, S. M., and Bellamkonda, R. V. (2004). Modulation of Rho GTPase activity alleviates chondroitin sulfate proteoglycan-dependent inhibition of neurite extension. J. Neurosci. Res. 77, 299-307. doi: 10.1002/jnr. 20161

Jin, L. Q., Zhang, G., Jamison, C. Jr., Takano, H., Haydon, P. G., and Selzer, M. E. (2009). Axon regeneration in the absence of growth cones: acceleration by cyclic AMP. J. Comp. Neurol. 515, 295-312. doi: 10.1002/cne.22057

Johnson, K. G., Tenney, A. P., Ghose, A., Duckworth, A. M., Higashi, M. E., Parfitt, K., et al. (2006). The HSPGs Syndecan and Dallylike bind the receptor phosphatase LAR and exert distinct effects on synaptic development. Neuron 49, 517-531. doi: 10.1016/j.neuron.2006.01.026

Jones, L. L., Margolis, R. U., and Tuszynski, M. H. (2003). The chondroitin sulfate proteoglycans neurocan, brevican, phosphacan, and versican are differentially regulated following spinal cord injury. Exp. Neurol. 182, 399-411. doi: 10.1016/s0014-4886(03)00087-6

Kaneko, M., Kubo, T., Hata, K., Yamaguchi, A., and Yamashita, T. (2007). Repulsion of cerebellar granule neurons by chondroitin sulfate proteoglycans is mediated by MAPK pathway. Neurosci. Lett. 423, 62-67. doi: 10.1016/j.neulet. 2007.06.038
Kantor, D. B., Chivatakarn, O., Peer, K. L., Oster, S. F., Inatani, M., Hansen, M. J., et al. (2004). Semaphorin 5A is a bifunctional axon guidance cue regulated by heparan and chondroitin sulfate proteoglycans. Neuron 44, 961-975. doi: 10.1016/j.neuron.2004.12.002

Kim, Y. H., Ha, K. Y., and Kim, S. I. (2017). Spinal cord injury and related clinical trials. Clin. Orthop. Surg. 9, 1-9. doi: 10.4055/cios.2017.9.1.1

Klein, R. (2004). Eph/ephrin signaling in morphogenesis, neural development and plasticity. Curr. Opin. Cell Biol. 16, 580-589. doi: 10.1016/j.ceb.2004.07.002

Ko, J. S., Pramanik, G., Um, J. W., Shim, J. S., Lee, D., Kim, K. H., et al. (2015). PTPsigma functions as a presynaptic receptor for the glypican4/LRRTM4 complex and is essential for excitatory synaptic transmission. Proc. Natl. Acad. Sci. U S A 112, 1874-1879. doi: 10.1073/pnas.1410138112

Kopp, M. A., Liebscher, T., Watzlawick, R., Martus, P., Laufer, S., Blex, C., et al. (2016). SCISSOR-spinal cord injury study on small moleculederived Rho inhibition: a clinical study protocol. BMJ Open 6:e010651. doi: 10.1136/bmjopen-2015-010651

Koprivica, V., Cho, K. S., Park, J. B., Yiu, G., Atwal, J., Gore, B., et al. (2005). EGFR activation mediates inhibition of axon regeneration by myelin and chondroitin sulfate proteoglycans. Science 310, 106-110. doi: 10.1126/science. 1115462

Kubo, T., and Yamashita, T. (2007). Rho-ROCK inhibitors for the treatment of CNS injury. Recent Pat. CNS Drug Discov. 2, 173-179. doi: $10.2174 / 157488907782411738$

Kwok, J. C., Dick, G., Wang, D., and Fawcett, J. W. (2011). Extracellular matrix and perineuronal nets in CNS repair. Dev. Neurobiol. 71, 1073-1089. doi: 10.1002/dneu.20974

Lang, B. T., Cregg, J. M., DePaul, M. A., Tran, A. P., Xu, K., Dyck, S. M., et al. (2015). Modulation of the proteoglycan receptor PTPsigma promotes recovery after spinal cord injury. Nature 518, 404-408. doi: 10.1038/nature13974

Ledig, M. M., Haj, F., Bixby, J. L., Stoker, A. W., and Mueller, B. K. (1999). The receptor tyrosine phosphatase CRYP $\alpha$ promotes intraretinal axon growth. J. Cell Biol. 147, 375-388. doi: 10.1083/jcb.147.2.375

Lee, D. H., Luo, X., Yungher, B. J., Bray, E., Lee, J. K., and Park, K. K. (2014). Mammalian target of rapamycin's distinct roles and effectiveness in promoting compensatory axonal sprouting in the injured CNS. J. Neurosci. 34 , 15347-15355. doi: 10.1523/JNEUROSCI.1935-14.2014

Lee, S. I., Zhang, W., Ravi, M., Weschenfelder, M., Bastmeyer, M., and Levine, J. M. (2013). Atypical protein kinase C and Par3 are required for proteoglycan-induced axon growth inhibition. J. Neurosci. 33, 2541-2554. doi: 10.1523/jneurosci.3154-12.2013

Lehmann, M., Fournier, A., Selles-Navarro, I., Dergham, P., Sebok, A., Leclerc, N., et al. (1999). Inactivation of Rho signaling pathway promotes CNS axon regeneration. J. Neurosci. 19, 7537-7547. doi: 10.1523/JNEUROSCI.19-1707537.1999

Leinster, V. H., Joy, M. T., Vuononvirta, R. E., Bolsover, S. R., and Anderson, P. N. (2013). ErbB1 epidermal growth factor receptor is a valid target for reducing the effects of multiple inhibitors of axonal regeneration. Exp. Neurol. 239, 82-90. doi: 10.1016/j.expneurol.2012.09.007

Liu, B. P., Cafferty, W. B., Budel, S. O., and Strittmatter, S. M. (2006). Extracellular regulators of axonal growth in the adult central nervous system. Philos. Trans. R. Soc. Lond. B Biol. Sci. 361, 1593-1610. doi: 10.1098/rstb.2006.1891

Liu, K., Lu, Y., Lee, J. K., Samara, R., Willenberg, R., Sears-Kraxberger, I., et al. (2010). PTEN deletion enhances the regenerative ability of adult corticospinal neurons. Nat. Neurosci. 13, 1075-1081. doi: 10.1038/nn.2603

Lord-Fontaine, S., Yang, F., Diep, Q., Dergham, P., Munzer, S., Tremblay, P., et al. (2008). Local inhibition of Rho signaling by cell-permeable recombinant protein BA-210 prevents secondary damage and promotes functional recovery following acute spinal cord injury. J. Neurotrauma 25, 1309-1322. doi: $10.1089 /$ neu.2008.0613

Luo, L. (2000). Rho GTPases in neuronal morphogenesis. Nat. Rev. Neurosci. 1, 173-180. doi: $10.1038 / 35044547$

Maekawa, M., Ishizaki, T., Boku, S., Watanabe, N., Fujita, A., Iwamatsu, A., et al. (1999). Signaling from Rho to the actin cytoskeleton through protein kinases ROCK and LIM-kinase. Science 285, 895-898. doi: 10.1126/science.285. 5429.895

McGee, A. W., and Strittmatter, S. M. (2003). The Nogo-66 receptor: focusing myelin inhibition of axon regeneration. Trends Neurosci. 26, 193-198. doi: 10.1016/s0166-2236(03)00062-6 
McKeon, R. J., Schreiber, R. C., Rudge, J. S., and Silver, J. (1991). Reduction of neurite outgrowth in a model of glial scarring following CNS injury is correlated with the expression of inhibitory molecules on reactive astrocytes. J. Neurosci. 11, 3398-3411. doi: 10.1523/jneurosci.11-11-03398.1991

McKerracher, L., and Anderson, K. D. (2013). Analysis of recruitment and outcomes in the phase I/IIa Cethrin clinical trial for acute spinal cord injury. J. Neurotrauma 30, 1795-1804. doi: 10.1089/neu.2013.2909

McKerracher, L., and Higuchi, H. (2006). Targeting Rho to stimulate repair after spinal cord injury. J. Neurotrauma 23, 309-317. doi: 10.1089/neu.2006.23.309

McLean, J., Batt, J., Doering, L. C., Rotin, D., and Bain, J. R. (2002). Enhanced rate of nerve regeneration and directional errors after sciatic nerve injury in receptor protein tyrosine phosphatase sigma knock-out mice. J. Neurosci. 22, 5481-5491. doi: 10.1523/jneurosci.22-13-05481.2002

Meijer, L., Flajolet, M., and Greengard, P. (2004). Pharmacological inhibitors of glycogen synthase kinase 3. Trends Pharmacol. Sci. 25, 471-480. doi: 10.1016/j. tips.2004.07.006

Monnier, P. P., Sierra, A., Schwab, J. M., Henke-Fahle, S., and Mueller, B. K. (2003). The Rho/ROCK pathway mediates neurite growth-inhibitory activity associated with the chondroitin sulfate proteoglycans of the CNS glial scar. Mol. Cell. Neurosci. 22, 319-330. doi: 10.1016/s1044-7431(02)00035-0

Mothe, A. J., Tassew, N. G., Shabanzadeh, A. P., Penheiro, R., Vigouroux, R. J., Huang, L., et al. (2017). RGMa inhibition with human monoclonal antibodies promotes regeneration, plasticity and repair and attenuates neuropathic pain after spinal cord injury. Sci. Rep. 7:10529. doi: 10.1038/s41598-017-10987-7

Mueller, B. K., Mack, H., and Teusch, N. (2005). Rho kinase, a promising drug target for neurological disorders. Nat. Rev. Drug Discov. 4, 387-398. doi: $10.1038 / \mathrm{nrd} 1719$

Nagai, J., Takaya, R., Piao, W., Goshima, Y., and Ohshima, T. (2016). Deletion of Crmp4 attenuates CSPG-induced inhibition of axonal growth and induces nociceptive recovery after spinal cord injury. Mol. Cell. Neurosci. 74, 42-48. doi: 10.1016/j.mcn.2016.03.006

Nakamura, F., Okada, T., Shishikura, M., Uetani, N., Taniguchi, M., Yagi, T., et al. (2017). Protein tyrosine phosphatase delta mediates the Sema3Ainduced cortical basal dendritic arborization through the activation of Fyn tyrosine kinase. J. Neurosci. 37, 7125-7139. doi: 10.1523/JNEUROSCI.2519 $-16.2017$

Niederöst, B., Oertle, T., Fritsche, J., McKinney, R. A., and Bandtlow, C. E. (2002). Nogo-A and myelin-associated glycoprotein mediate neurite growth inhibition by antagonistic regulation of RhoA and Racl. J. Neurosci. 22, 10368-10376. doi: 10.1523/jneurosci.22-23-10368.2002

Ohtake, Y., and Li, S. (2015). Molecular mechanisms of scar-sourced axon growth inhibitors. Brain Res. 1619, 22-35. doi: 10.1016/j.brainres.2014.08.064

Ohtake, Y., Sami, A., Jiang, X., Horiuchi, M., Slattery, K., Ma, L., et al. (2019). Promoting axon regeneration in adult CNS by targeting liver kinase B1. Mol. Ther. 27, 102-117. doi: 10.1016/j.ymthe.2018.10.019

Ohtake, Y., Wong, D., Abdul-Muneer, P. M., Selzer, M. E., and Li, S. (2016). Two PTP receptors mediate CSPG inhibition by convergent and divergent signaling pathways in neurons. Sci. Rep. 6:37152. doi: 10.1038/srep37152

Park, K. K., Liu, K., Hu, Y., Kanter, J. L., and He, Z. (2010). PTEN/mTOR and axon regeneration. Exp. Neurol. 223, 45-50. doi: 10.1016/j.expneurol.2009.12.032

Park, K. K., Liu, K., Hu, Y., Smith, P. D., Wang, C., Cai, B., et al. (2008). Promoting axon regeneration in the adult CNS by modulation of the PTEN/mTOR pathway. Science 322, 963-966. doi: 10.1126/science.1161566

Petratos, S., Li, Q. X., George, A. J., Hou, X., Kerr, M. L., Unabia, S. E., et al. (2008). The $\beta$-amyloid protein of Alzheimer's disease increases neuronal CRMP-2 phosphorylation by a Rho-GTP mechanism. Brain 131, 90-108. doi: 10.1093/brain/awm260

Powell, E. M., Mercado, M. L., Calle-Patino, Y., and Geller, H. M. (2001). Protein kinase C mediates neurite guidance at an astrocyte boundary. Glia 33, 288-297. doi: 10.1002/1098-1136(20010315)33:4<288::aid-glia1027>3.0.co;2-r

Rodemer, W., Zhang, G., Sinitsa, I., Hu, J., Jin, L. Q., Li, S., et al. (2020). PTPsigma knockdown in lampreys impairs reticulospinal axon regeneration and neuronal survival after spinal cord injury. Front. Cell. Neurosci. 14:61. doi: 10.3389/fncel. 2020.00061

Rodriguez, O. C., Schaefer, A. W., Mandato, C. A., Forscher, P., Bement, W. M., and Waterman-Storer, C. M. (2003). Conserved microtubule-actin interactions in cell movement and morphogenesis. Nat. Cell Biol. 5, 599-609. doi: $10.1038 /$ ncb0703-599
Sapieha, P. S., Duplan, L., Uetani, N., Joly, S., Tremblay, M. L., Kennedy, T. E., et al. (2005). Receptor protein tyrosine phosphatase sigma inhibits axon regrowth in the adult injured CNS. Mol. Cell. Neurosci. 28, 625-635. doi: 10.1016/j.mcn. 2004.10.011

Sharma, K., Selzer, M. E., and Li, S. (2012). Scar-mediated inhibition and CSPG receptors in the CNS. Exp. Neurol. 237, 370-378. doi: 10.1016/j.expneurol.2012. 07.009

Shelly, M., Cancedda, L., Heilshorn, S., Sumbre, G., and Poo, M. M. (2007). LKB1/STRAD promotes axon initiation during neuronal polarization. Cell 129, 565-577. doi: 10.1016/j.cell.2007.04.012

Shen, Y., Tenney, A. P., Busch, S. A., Horn, K. P., Cuascut, F. X., Liu, K., et al. (2009). PTPsigma is a receptor for chondroitin sulfate proteoglycan, an inhibitor of neural regeneration. Science 326, 592-596. doi: 10.1126/science. 1178310

Sherman, L. S., and Back, S. A. (2008). A 'GAG' reflex prevents repair of the damaged CNS. Trends Neurosci. 31, 44-52. doi: 10.1016/j.tins.2007.11.001

Shifman, M. I., Yumul, R. E., Laramore, C., and Selzer, M. E. (2009). Expression of the repulsive guidance molecule RGM and its receptor neogenin after spinal cord injury in sea lamprey. Exp. Neurol. 217, 242-251. doi: 10.1016/j.expneurol. 2009.02.011

Silver, L., Michael, J. V., Goldfinger, L. E., and Gallo, G. (2014). Activation of PI3K and R-Ras signaling promotes the extension of sensory axons on inhibitory Chondroitin sulfate proteoglycans. Dev. Neurobiol. 74, 918-933. doi: 10.1002/dneu.22174

Siu, R., Fladd, C., and Rotin, D. (2007). N-cadherin is an in vivo substrate for protein tyrosine phosphatase sigma (PTPsigma) and participates in PTPsigma-mediated inhibition of axon growth. Mol. Cell. Biol. 27, 208-219. doi: $10.1128 / \mathrm{mcb} .00707-06$

Sivasankaran, R., Pei, J., Wang, K. C., Zhang, Y. P., Shields, C. B., Xu, X. M., et al. (2004). PKC mediates inhibitory effects of myelin and chondroitin sulfate proteoglycans on axonal regeneration. Nat. Neurosci. 7, 261-268. doi: $10.1038 / \mathrm{nn} 1193$

Sladojevic, N., Yu, B., and Liao, J. K. (2017). ROCK as a therapeutic target for ischemic stroke. Expert Rev. Neurother. 17, 1167-1177. doi: 10.1080/14737175. 2017.1395700

Smith, J. A., Poteet-Smith, C. E., Malarkey, K., and Sturgill, T. W. (1999). Identification of an extracellular signal-regulated kinase (ERK) docking site in ribosomal S6 kinase, a sequence critical for activation by ERK in vivo. J. Biol. Chem. 274, 2893-2898. doi: 10.1074/jbc.274.5.2893

Snow, D. M., Lemmon, V., Carrino, D. A., Caplan, A. I., and Silver, J. (1990). Sulfated proteoglycans in astroglial barriers inhibit neurite outgrowth in vitro. Exp. Neurol. 109, 111-130. doi: 10.1016/s0014-4886(05)80013-5

Sotogaku, N., Tully, S. E., Gama, C. I., Higashi, H., Tanaka, M., HsiehWilson, L. C., et al. (2007). Activation of phospholipase C pathways by a synthetic chondroitin sulfate-E tetrasaccharide promotes neurite outgrowth of dopaminergic neurons. J. Neurochem. 103, 749-760. doi: 10.1111/j.1471-4159. 2007.04849.x

Stern, S., and Knöll, B. (2014). CNS axon regeneration inhibitors stimulate an immediate early gene response via MAP kinase-SRF signaling. Mol. Brain 7:86. doi: 10.1186/s13041-014-0086-6

$\mathrm{Su}, \mathrm{H} ., \mathrm{Chu}, \mathrm{T} . \mathrm{H}$, and $\mathrm{Wu}, \mathrm{W}$. (2007). Lithium enhances proliferation and neuronal differentiation of neural progenitor cells in vitro and after transplantation into the adult rat spinal cord. Exp. Neurol. 206, 296-307. doi: 10.1016/j.expneurol.2007.05.018

Tan, C. L., Kwok, J. C., Patani, R., Ffrench-Constant, C., Chandran, S., and Fawcett, J. W. (2011). Integrin activation promotes axon growth on inhibitory chondroitin sulfate proteoglycans by enhancing integrin signaling. J. Neurosci. 31, 6289-6295. doi: 10.1523/jneurosci.0008-11.2011

Tedeschi, A., Dupraz, S., Curcio, M., Laskowski, C. J., Schaffran, B., Flynn, K. C., et al. (2019). ADF/cofilin-mediated actin turnover promotes axon regeneration in the adult CNS. Neuron 103, 1073.e6-1085.e6. doi: 10.1016/j.neuron.2019. 07.007

Thompson, K. M., Uetani, N., Manitt, C., Elchebly, M., Tremblay, M. L., and Kennedy, T. E. (2003). Receptor protein tyrosine phosphatase sigma inhibits axonal regeneration and the rate of axon extension. Mol. Cell. Neurosci. 23, 681-692. doi: 10.1016/s1044-7431(03)00120-9

Tran, A. P., Warren, P. M., and Silver, J. (2020). Regulation of autophagy by inhibitory CSPG interactions with receptor PTPsigma and its impact on 
plasticity and regeneration after spinal cord injury. Exp. Neurol. 328:113276. doi: 10.1016/j.expneurol.2020.113276

Uchida, Y., Ohshima, T., Sasaki, Y., Suzuki, H., Yanai, S., Yamashita, N., et al. (2005). Semaphorin3A signalling is mediated via sequential Cdk5 and GSK3 $\beta$ phosphorylation of CRMP2: implication of common phosphorylating mechanism underlying axon guidance and Alzheimer's disease. Genes Cells 10, 165-179. doi: 10.1111/j.1365-2443.2005.00827.x

Urban, M. W., Ghosh, B., Block, C. G., Charsar, B. A., Smith, G. M., Wright, M. C., et al. (2019a). Protein tyrosine phosphatase sigma inhibitory peptide promotes recovery of diaphragm function and sprouting of bulbospinal respiratory axons after cervical spinal cord injury. J. Neurotrauma 37, 572-579. doi: 10.1089/neu. 2019.6586

Urban, M. W., Ghosh, B., Block, C. G., Strojny, L. R., Charsar, B. A., Goulao, M., et al. (2019b). Long-distance axon regeneration promotes recovery of diaphragmatic respiratory function after spinal cord injury. eNeuro 6:ENEURO.0096-19.2019. doi: 10.1523/eneuro.0096-19.2019

Venkatesh, K., Chivatakarn, O., Lee, H., Joshi, P. S., Kantor, D. B., Newman, B. A., et al. (2005). The Nogo-66 receptor homolog NgR2 is a sialic acid-dependent receptor selective for myelin-associated glycoprotein. J. Neurosci. 25, 808-822. doi: 10.1523/jneurosci.4464-04.2005

Wakatsuki, S., Saitoh, F., and Araki, T. (2011). ZNRF1 promotes Wallerian degeneration by degrading AKT to induce GSK3B-dependent CRMP2 phosphorylation. Nat. Cell Biol. 13, 1415-1423. doi: 10.1038/ncb2373

Walker, B. A., Ji, S. J., and Jaffrey, S. R. (2012). Intra-axonal translation of RhoA promotes axon growth inhibition by CSPG. J. Neurosci. 32, 14442-14447. doi: 10.1523/jneurosci.0176-12.2012

Wang, X., Budel, S., Baughman, K., Gould, G., Song, K. H., and Strittmatter, S. M. (2009). Ibuprofen enhances recovery from spinal cord injury by limiting tissue loss and stimulating axonal growth. J. Neurotrauma 26, 81-95. doi: 10.1089/neu.2007.0464

Wang, H., Katagiri, Y., McCann, T. E., Unsworth, E., Goldsmith, P., Yu, Z. X., et al. (2008). Chondroitin-4-sulfation negatively regulates axonal guidance and growth. J. Cell Sci. 121, 3083-3091. doi: 10.1242/jcs.032649

Wang, S., Smith, G. M., Selzer, M. E., and Li, S. (2019). Emerging molecular therapeutic targets for spinal cord injury. Expert Opin. Ther. Targets 23, 787-803. doi: 10.1080/14728222.2019.1661381

Wang, X. W., Yang, S. G., Zhang, C., Hu, M. W., Qian, J., Ma, J. J., et al. (2020). Knocking out non-muscle myosin II in retinal ganglion cells promotes long-distance optic nerve regeneration. Cell Rep. 31:107537. doi: $10.1101 / 625707$

Watzlawick, R., Sena, E. S., Dirnagl, U., Brommer, B., Kopp, M. A., Macleod, M. R., et al. (2014). Effect and reporting bias of RhoA/ROCK-blockade intervention on locomotor recovery after spinal cord injury: a systematic review and metaanalysis. JAMA Neurol. 71, 91-99. doi: 10.1001/jamaneurol.2013.4684

Wong, V. S. C., Picci, C., Swift, M., Levinson, M., Willis, D., and Langley, B. (2018). $\alpha$-tubulin acetyltransferase is a novel target mediating neurite growth inhibitory effects of chondroitin sulfate proteoglycans and myelin-associated glycoprotein. eNeuro 5:ENEURO.0240-17.2018. doi: 10.1523/eneuro.0240 $-17.2018$

Wong, Y. W., Tam, S., So, K. F., Chen, J. Y., Cheng, W. S., Luk, K. D., et al. (2011). A three-month, open-label, single-arm trial evaluating the safety and pharmacokinetics of oral lithium in patients with chronic spinal cord injury. Spinal Cord 49, 94-98. doi: 10.1038/sc.2010.69

Wu, K. Y., Hengst, U., Cox, L. J., Macosko, E. Z., Jeromin, A., Urquhart, E. R., et al. (2005). Local translation of RhoA regulates growth cone collapse. Nature 436, 1020-1024. doi: 10.1038/nature03885

Xu, B., Park, D., Ohtake, Y., Li, H., Hayat, U., Liu, J., et al. (2015). Role of CSPG receptor LAR phosphatase in restricting axon regeneration after CNS injury. Neurobiol. Dis. 73, 36-48. doi: 10.1016/j.nbd.2014. 08.030

Yamaguchi, Y. (2000). Lecticans: organizers of the brain extracellular matrix. Cell. Mol. Life Sci. 57, 276-289. doi: 10.1007/pl00000690

Yang, M. L., Li, J. J., So, K. F., Chen, J. Y., Cheng, W. S., Wu, J., et al. (2012). Efficacy and safety of lithium carbonate treatment of chronic spinal cord injuries: a double-blind, randomized, placebo-controlled clinical trial. Spinal Cord 50, 141-146. doi: 10.1038/sc.2011.126

Yang, L., Miao, L., Liang, F., Huang, H., Teng, X., Li, S., et al. (2014). The mTORC1 effectors S6K1 and 4E-BP play different roles in CNS axon regeneration. Nat. Commun. 5:5416. doi: 10.1038/ncomms6416

Yu, P., Pearson, C. S., and Geller, H. M. (2017). Flexible roles for proteoglycan sulfation and receptor signaling. Trends Neurosci. 41, 47-61. doi: 10.1016/j.tins. 2017.10.005

Yu, P., Santiago, L. Y., Katagiri, Y., and Geller, H. M. (2012). Myosin II activity regulates neurite outgrowth and guidance in response to chondroitin sulfate proteoglycans. J. Neurochem. 120, 1117-1128. doi: 10.1111/j.1471-4159.2011. 07638.x

Zhang, G., Hu, J., Li, S., Huang, L., and Selzer, M. E. (2014). Selective expression of CSPG receptors $\mathrm{PTP} \sigma$ and LAR in poorly regenerating reticulospinal neurons of lamprey. J. Comp. Neurol. 522, 2209-2229. doi: 10.1002/cne.23529

Zhang, G., Hu, J., Rodemer, W., Li, S., and Selzer, M. E. (2018). RhoA activation in axotomy-induced neuronal death. Exp. Neurol. 306, 76-91. doi: 10.1016/j. expneurol.2018.04.015

Zhang, R., Wu, Y., Xie, F., Zhong, Y., Wang, Y., Xu, M., et al. (2018). RGMa mediates reactive astrogliosis and glial scar formation through TGF $\beta 1 /$ Smad2/3 signaling after stroke. Cell Death Differ. 25, 1503-1516. doi: 10.1038/s41418-018-0058-y

Zhang, Z., Ottens, A. K., Larner, S. F., Kobeissy, F. H., Williams, M. L., Hayes, R. L., et al. (2006). Direct Rho-associated kinase inhibition [correction of inhibiton] induces cofilin dephosphorylation and neurite outgrowth in PC-12 cells. Cell. Mol. Biol. Lett. 11, 12-29. doi: 10.2478/s11658-006-0002-x

Zheng, B., Jeong, J. H., Asara, J. M., Yuan, Y. Y., Granter, S. R., Chin, L., et al. (2009). Oncogenic B-RAF negatively regulates the tumor suppressor LKB1 to promote melanoma cell proliferation. Mol. Cell 33, 237-247. doi: 10.1016/j. molcel.2008.12.026

Zhou, Y., Su, Y., Li, B., Liu, F., Ryder, J. W., Wu, X., et al. (2003). Nonsteroidal anti-inflammatory drugs can lower amyloidogenic $\mathrm{A} \beta 42$ by inhibiting Rho. Science 302, 1215-1217. doi: 10.1126/science.1090154

Zhou, F. Q., Walzer, M., Wu, Y. H., Zhou, J., Dedhar, S., and Snider, W. D. (2006). Neurotrophins support regenerative axon assembly over CSPGs by an ECMintegrin-independent mechanism. J. Cell Sci. 119, 2787-2796. doi: 10.1242/jcs. 03016

Zhu, H., Poon, W., Liu, Y., Leung, G. K., Wong, Y., Feng, Y., et al. (2016). Phase I-II clinical trial assessing safety and efficacy of umbilical cord blood mononuclear cell transplant therapy of chronic complete spinal cord injury. Cell Transplant 25, 1925-1943. doi: 10.3727/096368916x691411

Conflict of Interest: The authors declare that the research was conducted in the absence of any commercial or financial relationships that could be construed as a potential conflict of interest.

Copyright $\odot 2020$ Sami, Selzer and Li. This is an open-access article distributed under the terms of the Creative Commons Attribution License (CC BY). The use, distribution or reproduction in other forums is permitted, provided the original author(s) and the copyright owner(s) are credited and that the original publication in this journal is cited, in accordance with accepted academic practice. No use, distribution or reproduction is permitted which does not comply with these terms. 